\title{
ASPECTOS AMBIENTAIS E QUALIDADE DAS ÁGUAS SUPERFICIAIS NA \\ BACIA HIDROGRÁFICA DO RIO CURU - CEARÁ - BRASIL $^{1}$
}

\author{
ENVIRONMENTAL ASPECTS AND QUALITY OF \\ SURFACE WATERS IN THE HYDROGRAPHIC BASIN OF \\ THE CURU RIVER - CEARÁ - BRAZIL
}

\section{Gorayeb, A., Gomes, R.B., Araújo, L.F.P., Souza, M.J.N., Rosa, M.F.; Figueirêdo, M.C.B.}

${ }^{1}$ Universidade Federal do Pará. Alameda Leandro Ribeiro, s/n - Aldeia - 66600-000 - Braganças, PA. e-mail: adryanegorayeb@yahoo.com.br

${ }^{2,3,4}$ Centro Federal de Educação Tecnológica do Ceará - CEFET-CE. Av. 13 de Maio, 2081Benfica -60040-531 - Fortaleza, CE.

${ }^{5,6}$ Empresa Brasileira de Pesquisa Agropecuária, Centro Nacional de Pesquisa de Agroindústria Tropical, Centro Nacional de Pesquisa de Agroindústria Tropical. Rua Dra. Sara Mesquita, 2270 -Pici - 60511-110 - Fortaleza, CE - Caixa-Postal: 3761

\section{RESUMO}

Desde 1932, a bacia hidrográfica do rio Curu vem sendo alvo de intervenções governamentais tanto em âmbito federal como estadual. Destaca-se dentre as outras bacias do estado do Ceará por ter sido a primeira a implantar o sistema de perímetros irrigados, em 1975, bem como a primeira a organizar um Comitê de Bacia Hidrográfica, em 1996. Encontra-se atualmente com sérios problemas ambientais relacionados aos efeitos da utilização inadequada dos recursos naturais. A presente pesquisa teve por objetivo analisar a qualidade das águas superficiais do rio Curu e de seus principais reservatórios, considerando-se alguns parâmetros físicos, químicos e o teor de coliformes termotolerantes, segundo a Resolução $\mathrm{n}^{\circ} 357$ (CONSELHO NACIONAL DE MEIO AMBIENTE, 2005). Em campo foram identificados os principais fatores potenciais de degradação dos recursos hídricos superficiais da bacia através do método "listagem de controle" (check list). Foram definidos e georreferenciados 15 pontos de amostragem, envolvendo seções de rios e principais reservatórios, realizando-se cinco coletas de água com análises laboratoriais no período de um ano (fev./2003 a mar./2004). O estudo revelou que o crescimento 
econômico e demográfico da bacia vêm provocando a degradação dos recursos hídricos através do desmatamento da vegetação original, da ocupação das Áreas de Preservação Permanente (APP's), da precariedade na infra-estrutura dos serviços de saneamento básico e das atividades agrícolas mal planejadas. Tal fato é constatado através dos valores encontrados para os parâmetros analisados que não atendem aos padrões legais de referência da Resolução $n^{\circ} 357$ (CONSELHO NACIONAL DE MEIO AMBIENTE, 2005), para as águas doces de classe 2.

Palavras-Chave: Qualidade da água. Fatores de degradação. Impactos ambientais. Bacia hidrográfica. Nordeste do Brasil.

\begin{abstract}
Since 1932, the Curu River watershed has received assistance from the Federal and the State government. It stands out among other Ceara watersheds and has been the first to implement the irrigated perimeter system (1975) and also to organise a Watershed Committee (1996). Nowadays, it has serious environmental problems related to the effects of inadequate use of the natural resources. Thus, the objective of this investigation was to analyse physico-chemical and microbiological parameters in sections of rivers of the Curu basin, using Resolution $\mathrm{n}^{\circ} 357$ (CONSELHO NACIONAL DE MEIO AMBIENTE, 2005) as the main reference. In the field, the main potential factors in the degradation of surface waters in the watershed were identified through the check list method, and 15 sampling stations in river sections were defined and located geographically. Five collections of water samples were taken and analyzed in the laboratory over a period of one year (feb./2003 to mar./2004). During this study, it was observed that the degradation of water resources increases with economic and demographic development of the Curu basin, because of the devastation of the original vegetation and the contamination of the surface water with draining from urban and rural activities.
\end{abstract}

Keywords: Water quality. Factors of degradation. Environment impact. River hydrographic basin. Northeast of Brazil

\title{
1. INTRODUÇÃO
}

As bacias hidrográficas apresentam-se como unidades fundamentais para o gerenciamento dos recursos hídricos e para o planejamento ambiental, já que se mostram extremamente vulneráveis às atividades antrópicas (DIETRICH et al., 2004). De modo geral, as regiões hidrográficas nordestinas têm sofrido grande perda da biodiversidade relacionada à crescente necessidade da sociedade por água, 
alimentos, madeiras, fibras, minérios e outros produtos advindos da exploração dos recursos naturais.

Na gestão integrada de bacias hidrográficas, o monitoramento da água, seja no aspecto quantitativo ou qualitativo, fundamenta a tomada de decisões e previne conflitos entre usuários, evidenciados especialmente no semi-árido nordestino, onde as características ambientais do meio físico geram problemáticas bastante peculiares. O cenário de escassez dos recursos hídricos exige pesquisas de médio e longo prazos que avaliem a capacidade de suporte dos corpos de água e que subsidiem o desenvolvimento e a preservação ambiental dessas regiões, sendo necessário assim à geração de dados sistemáticos para fundamentar adequadamente as ações de planejamento.

No mapa hidrográfico do Ceará (Figura 1), pode-se destacar a bacia hidrográfica do Curu, que foi a primeira a constituir um Comitê de Bacia, e é considerada pelo Departamento Nacional de Obras Contra as Secas (DEPARTAMENTO NACIONAL DE OBRAS CONTRA AS SECAS, 1993) a bacia modelo do Estado. Possui dois perímetros de irrigação: Curu-Paraipaba e CuruPentecoste que estão economicamente relacionados à fruticultura, às culturas de subsistência e, de modo mais expressivo, aos cultivos de cana-de-açúcar e de cocoda-baía.

Apesar de possuírem considerável número de obras hidráulicas, os quinze municípios da bacia (Itatira, Canindé, Caridade, Paramoti, General Sampaio, Tejuçuoca, Apuiarés, Irauçuba, Itapajé, Pentecoste, Umirim, São Luís do Curu, São Gonçalo do Amarante, Paracuru e Paraipaba), de modo geral, sofrem com a escassez hídrica qualitativa e quantitativa, tendo que recorrer ao abastecimento por carros-pipa durante os períodos mais críticos de estiagem. Isso ocorre por causa da precária estrutura do sistema público de distribuição de água que privilegia a área urbana em detrimento da zona rural, da incipiente gestão dos recursos hídricos, do crescimento desordenado da irrigação, da ineficiência do manejo agrícola, da falta de esclarecimento da população quanto às questões ambientais e das próprias condições climáticas regionais.

De acordo com dados do IBGE (INSTITUTO BRASILEIRO DE GEOGRAFIA E ESTATÍSTICA, 2000), no ano de 2000 existiam 79.697 domicílios na área urbana dos municípios da bacia do rio Curu, dos quais apenas $65 \%$ possuíam banheiro, $42,5 \%$ eram beneficiados pela coleta de lixo, $45,5 \%$ eram servidos pela rede geral de água e somente $5,5 \%$ possuíam banheiro com sistema completo de água e esgoto (INSTITUTO BRASILEIRO DE GEOGRAFIA E ESTATÍSTICA, 2000). A respeito do tratamento dos resíduos sólidos, verificou-se que 93\% das sedes municipais utilizavam lixões a céu aberto e somente um município possuía aterro controlado com licença ambiental do estado (GORAYEB, 2004).

$\mathrm{Na}$ zona rural da bacia, dados de Lucena et al. (2004) mostram que no ano de 2000 a rede de abastecimento de água cobria apenas 4\% dos domicílios e somente 
$1 \%$ era atendido pela coleta sistemática de lixo, enquanto que o sistema público de esgotamento sanitário inexistia.

Nesse contexto, a presente pesquisa analisa a qualidade hídrica em seções de rios e em reservatórios da bacia do rio Curu e identifica os principais fatores que interferem nas características físicas, químicas e de qualidade sanitária da água, tendo como referência a Resolução $\mathrm{n}^{\circ} 357$ (CONSELHO NACIONAL DE MEIO AMBIENTE, 2005) que estabelece a classificação das águas doces, salobras e salinas no Território Nacional.

\section{METODOLOGIA}

\subsection{Caracterização da Área de Estudo}

A bacia hidrográfica do rio Curu está localizada na porção noroeste do estado

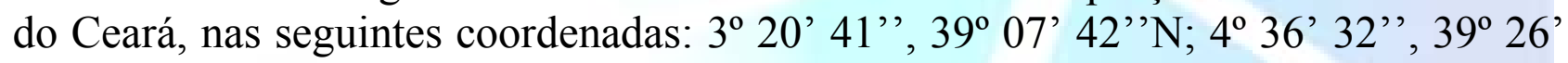

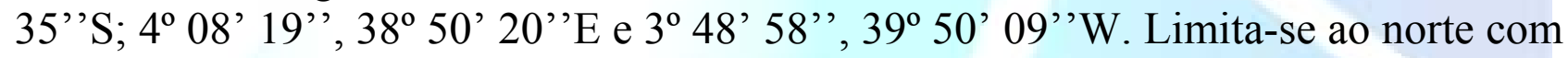
o Oceano Atlântico, a leste com a Bacia Metropolitana, a oeste com a Bacia do Litoral e ao sul com as Bacias do Acaraú e Banabuiú. A Figura 1 ilustra a localização geográfica da bacia do rio Curu, em relação às outras bacias do Estado e à Capital.

O principal rio da bacia é o Curu, que possui extensão linear de $195 \mathrm{~km}$, das nascentes à foz, onde deságua no litoral oeste do Ceará, entre os municípios de Paracuru e Paraipaba (GORAYEB, 2004). Seus afluentes mais significativos são os que comportam os principais açudes da bacia: Frios, Caxitoré e Tejuçuoca na margem esquerda e Canindé, Capitão-Mor e Melancia na margem direita. A região da bacia é composta por 15 municípios (Itatira, Canindé, Caridade, Paramoti, General Sampaio, Tejuçuoca, Apuiarés, Pentecoste, Itapajé, Irauçuba, Umirim, São Luís do Curu, São Gonçalo do Amarante, Paraipaba e Paracuru), que totalizam uma população de 353.345 habitantes, ou seja, aproximadamente $5 \%$ da população total cearense (INSTITUTO BRASILEIRO DE GEOGRAFIA E ESTATÍSTICA, 2000).

As nascentes fluviais estão localizadas na serra do Machado e atingem níveis altimétricos entre 700 a $800 \mathrm{~m}$ (FUNDAÇÃO INSTITUTO DE PLANEJAMENTO DO CEARÁ, 1989). Os principais divisores de água da bacia são o maciço de Baturité a leste e o de Uruburetama a oeste, além das nascentes (Serra do Machado). 


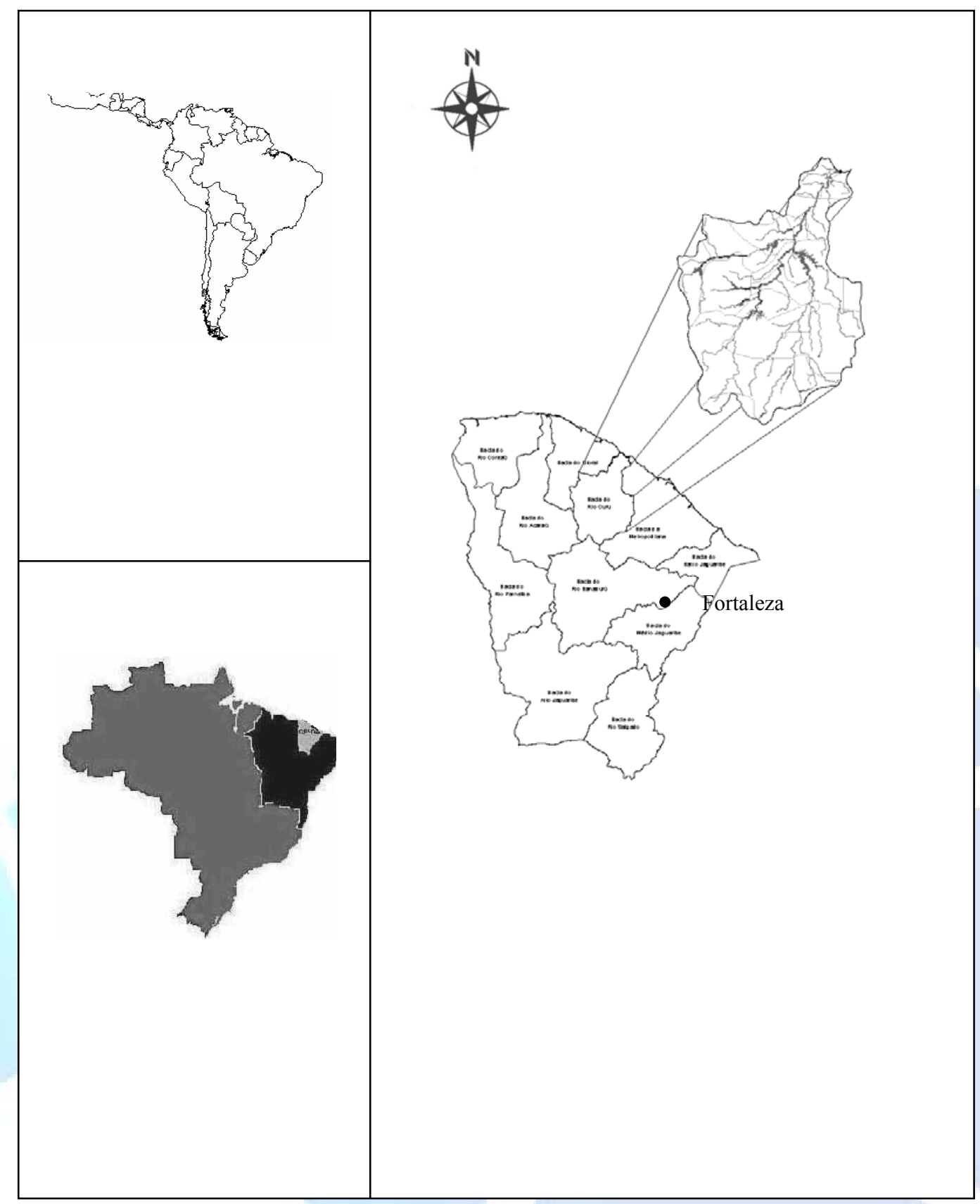

Figura 1. Localização geográfica da bacia hidrográfica do rio Curu, estado do Ceará. Fonte: adaptado de Cogerh (COMPANHIA DE GESTÃO DOS RECURSOS HÍDRICOS, 1996).

\subsection{Levantamento das Fontes Potenciais de Poluição}

Com a finalidade de identificar as principais fontes de poluição que afetam os corpos hídricos superficiais da bacia, empregou-se o método "listagem de controle" (check list). Durante os trabalhos de campo nas 13 sedes municipais foi utilizada uma lista padronizada com os principais fatores potenciais de poluição, exceção feita aos municípios de São Gonçalo do Amarante e Irauçuba, uma vez que suas sedes são drenadas pelas bacias Metropolitana e do Litoral, respectivamente. 


\subsection{Avaliação da Qualidade das Águas}

Para a análise da qualidade hídrica superficial foram definidas e georreferenciadas (GPS Garmin 72) em campo 15 pontos de amostragem em seções do rio e nos principais reservatórios ao longo da bacia, levando-se em consideração os usos, a influência dos núcleos urbanos e a existência de indústrias e de drenagens dos perímetros irrigados (Tabela 1 e Figura 2). Nesse contexto, é importante ressaltar que o ponto localizado no reservatório General Sampaio representou, ao mesmo tempo, um ponto de coleta (R-02) e o ponto inicial do trecho do rio Curu tomado durante o estudo (P-01).

Tabela 1 - Identificação dos pontos de coleta de água na bacia do Curu.

\begin{tabular}{c|l|l} 
Pontos de Coleta & \multicolumn{1}{|c}{ Trechos do rio Curu } & \multicolumn{1}{|c}{ Municípios } \\
\hline P-01 & Vertedouro Res. Gal.Sampaio - montante Sede & General Sampaio \\
\hline P-02 & À jusante da sede municipal & General Sampaio \\
\hline P-03 & À montante da sede municipal & Apuiarés \\
\hline P-04 & À jusante da sede municipal & Apuiarés \\
\hline P-05 & À montante da ponte Br-222 & São Luis do Curu \\
\hline P-06 & À montante das empresas Ypióca e Agrovale & Paraipaba \\
\hline P-07 & À jusante das empresas Ypióca e Agrovale & Paraipaba \\
\hline P-08 & Poço Doce - à jusante da sede municipal & Paraipaba \\
\hline P-09 & Ponto de drenagem do perímetro & Paraipaba \\
\hline & & \\
\hline R-01 & Açude São Mateus & Canindé \\
\hline R-02 & Açude General Sampaio & General Sampaio \\
\hline R-03 & Açude Tejuçuoca & Tejuçuoca \\
\hline R-04 & Açude Pereira de Miranda & Pentecoste \\
\hline R-05 & Açude Caxitoré & Umirim \\
\hline R-06 & Açude Frios & Umirim \\
\hline R-07 & Lagoa Cana-Brava & Paraipaba
\end{tabular}

No decorrer da pesquisa foram realizadas cinco coletas de água, no período de fevereiro/2003 a março/2004, com freqüência trimestral. As coletas contemplaram o período chuvoso (fevereiro a maio) e seco (junho a janeiro) do Estado e para cada amostra foram analisados parâmetros físicos, químicos e o teor de coliformes termotolerantes, cujas metodologias são apresentadas na Tabela 2.

Tabela 2 - Parâmetros analisados e respectivas metodologias analíticas referenciadas.

\begin{tabular}{|c|c|c|}
\hline Parâmetro & Metodologia & Referência \\
\hline Cor Aparente $(\mathrm{uH})$ & Colorimétrico & \multirow{7}{*}{$\begin{array}{l}\text { AMERICAN PUBLIC } \\
\text { HEALTH ASSOCIATION } \\
\text { et al.; (1998) }\end{array}$} \\
\hline Turbidez (uT) & Turbidimétrico & \\
\hline Oxigênio Dissolvido - OD $\left(\mathrm{mgO}_{2} / \mathrm{L}\right)$ & Winkler (via azida) & \\
\hline $\begin{array}{l}\text { Demanda Bioquímica de Oxigênio - } \\
\mathrm{DBO}_{5}\left(\mathrm{mgO}_{2} / \mathrm{L}\right)\end{array}$ & Incubação $\left(20^{\circ} \mathrm{C}, 5\right.$ dias $)$ & \\
\hline Fósforo Total (mg/L) & $\begin{array}{l}\text { Espectrofotometria Absorção Molecular - } \\
\text { Método Ácido Ascórbico }\end{array}$ & \\
\hline Coliformes Termotolerantes & Tubos múltiplos - Meio $\mathrm{A}_{1}$ & \\
\hline Amônia Total (mg/L) & $\begin{array}{l}\text { Espectrofotometria Absorção Molecular - } \\
\text { Nesslerização direta }\end{array}$ & \\
\hline
\end{tabular}


$\mathrm{Na}$ inexistência de enquadramento dos corpos de água no estado do Ceará, os padrões de referência utilizados foram os estabelecidos pela Resolução $\mathrm{n}^{\circ} 357$ (CONSELHO NACIONAL DE MEIO AMBIENTE, 2005) para as águas doces de Classe 2, as quais destinam-se: a) ao abastecimento para consumo humano, após tratamento convencional; b) à proteção das comunidades aquáticas; c) à recreação de contato primário, natação, esqui aquático e mergulho; d) à irrigação de hortaliças, plantas frutíferas e de parques, jardins, campos de esporte e lazer, com os quais o público possa vir a ter contato direto; e) à aqüicultura e à atividade de pesca.

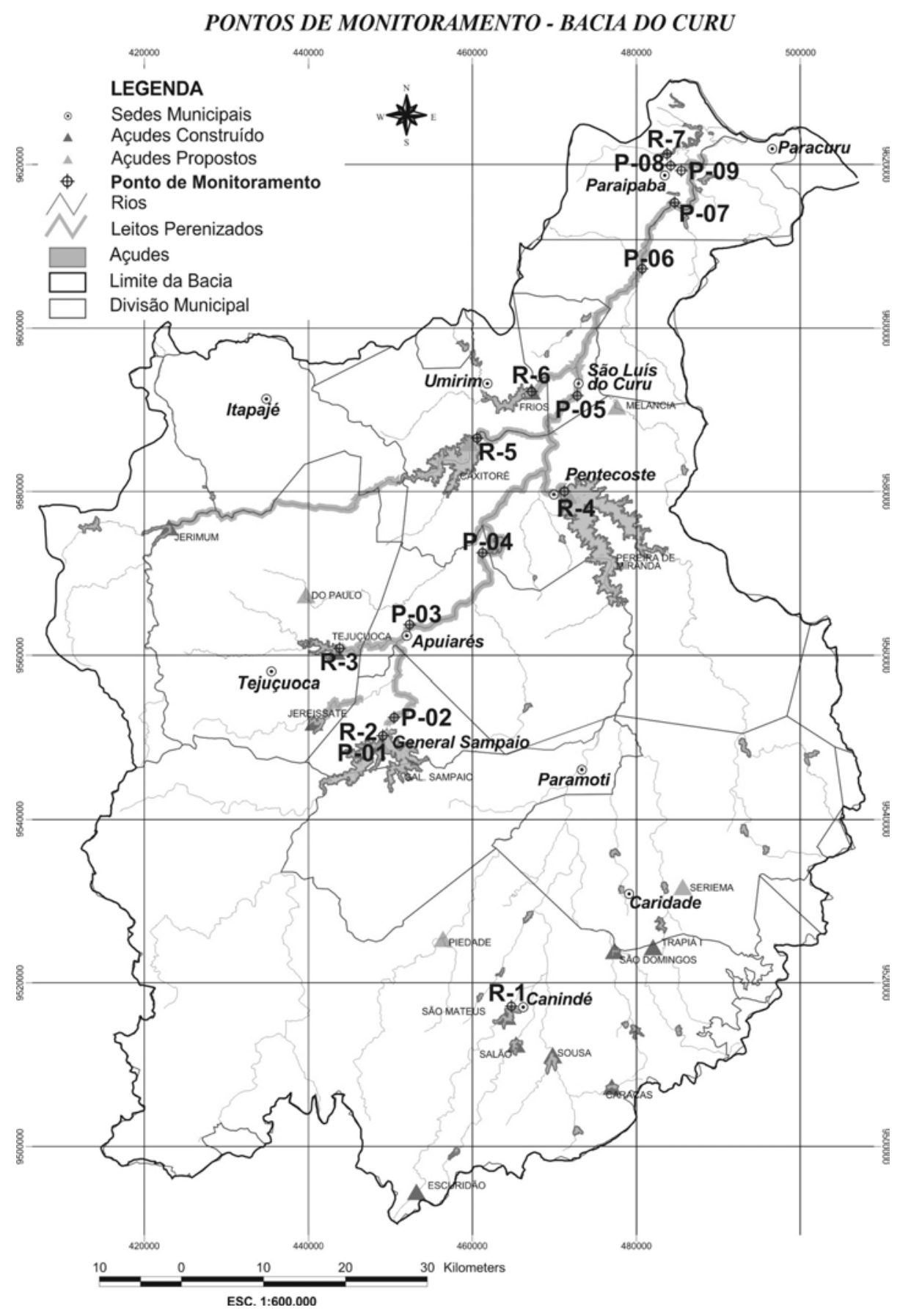

Figura 2. Localização geográfica dos pontos de amostragem na bacia do Curu. Fonte: Gorayeb (2004). 


\section{RESULTADOS E DISCUSSÃO}

\subsection{Levantamento das Fontes Potenciais de Poluição}

Com base nos resultados foi observado que do alto ao baixo curso do rio Curu, a qualidade da água da bacia é diretamente influenciada por fatores naturais, pela drenagem dos perímetros irrigados, pela atividade de aqüicultura e, principalmente, pela precária infra-estrutura de saneamento básico.

A estimativa do lixo produzido pelo total de habitantes em todos os municípios da bacia, conforme levantamento de campo, varia entorno de 353 a 530 t/dia, sendo que os lixões dos municípios de Itatira, Canindé, General Sampaio, Tejuçuoca e Itapajé estão localizados sobre ressurgências hídricas ou em trechos de riachos (afluentes dos principais tributários do rio Curu), aterrando-os e/ou contaminando-os.

A concessionária que administra os serviços de água e de esgoto das cidades é a Companhia de Água e Esgoto do Ceará, CAGECE (COMPANHIA DE ÁGUA E ESGOTO DO CEARÁ, 2004a), com exceção de Canindé e Itapajé que são administradas pelo Serviço Autônomo de Água e Esgoto (SAAE). O levantamento de dados revelou que somente quatro sedes municipais possuem sistema público de esgotamento sanitário com estação de tratamento: Canindé, Paracuru e Paraipaba, com o sistema de lagoas de estabilização, e Pentecoste com reator anaeróbio de manta de lodo associado a filtro. Paraipaba é o município com maior percentual de cobertura de esgoto, atendendo $64,8 \%$ da população total da sede do município (COMPANHIA DE ÁGUA E ESGOTO DO CEARÁ, 2004a).

Em Canindé o destino final dos efluentes tratados é o rio Canindé e nos municípios de Pentecoste e Paracuru é o rio Curu. Na cidade de Paraipaba o efluente da Estação de Tratamento de Esgoto (ETE) é utilizado para irrigar plantações de coqueiros e depois é drenado para um complexo de sistemas lacustres existente na área do perímetro irrigado Curu-Paraipaba. Em todas as ETE's citadas os resíduos sólidos gerados no tratamento (sólidos grosseiros, areia e lodo) têm como destino final o lixão. Quanto às outras nove sedes municipais, em alguns domicílios existem fossas sépticas, mas a maior parte das casas lança seus esgotos na rua, em canais a céu aberto, que escoam diretamente para o corpo hídrico mais próximo.

A estrutura sanitária dos matadouros públicos é precária, alguns sequer contam com água encanada e energia elétrica, operando em prédios construídos há mais de vinte anos, sem que tenham recebido qualquer tipo de manutenção ou reforma. Aqueles que utilizam água da rede pública não têm sistemas próprios de tratamento dos efluentes gerados no processo, drenando uma elevada carga orgânica para o rio Curu ou para alguns de seus principais tributários.

Os efluentes das lavagens dos filtros e dos decantadores das Estações de Tratamento de Água (ETA's), contendo altas concentrações de sulfato de alumínio, são despejados no próprio manancial público ou no terreno da concessionária. Tal fato, além de alterar a dinâmica natural da biota, pode prejudicar a atividade de 
irrigação, uma vez que as espécies vegetais apresentam baixo nível de tolerância ao alumínio.

Além de todas as problemáticas sanitárias e ambientais discutidas, os mananciais públicos da bacia ainda são utilizados, concomitantemente e de forma intensiva, para o abastecimento humano e para atividades potencialmente poluidoras como lavagem de carros e roupas, dessedentação e banho de animais e recreação de contato primário. Alguns pontos de captação sofrem ainda influência de agroquímicos advindos da drenagem dos perímetros irrigados e de áreas cultivadas às margens dos rios e no entorno de reservatórios, além de receberem efluentes da atividade de aqüicultura (carcinicultura e piscicultura) contendo resíduos de fertilizantes e restos de ração. Esses usos não planejados podem trazer prejuízos ao ambiente e à saúde humana, uma vez que os sistemas de tratamento de água adotados, na maioria das vezes, são insuficientes para atender aos padrões de potabilidade estabelecidos pela Portaria n. 518 (BRASIL, 2004).

\subsection{Qualidade das Águas Superficiais do Rio Curu}

O Gráfico 1 apresenta os valores médios de cor aparente e turbidez ao longo do rio Curu. Em relação à cor aparente, as análises revelaram que o único ponto que atendeu ao padrão estabelecido pela Resolução CONAMA n $357(75 \mathrm{mgPt} / \mathrm{L})$ encontra-se à jusante da sede municipal de Apuiarés (CONSELHO NACIONAL DE MEIO AMBIENTE, 2005). Os valores máximos foram observados nos pontos P-01 (199,3 mgPt/L) e P-09 (258,8 $\mathrm{mgPt} / \mathrm{L})$, respectivamente, vertedouro do reservatório General Sampaio e ponto de drenagem do perímetro irrigado Curu-Paraipaba.

Quanto a turbidez, todo o trecho amostrado atendeu ao padrão CONAMA (100 UNT), sendo que os valores médios mais altos obtidos também foram nos pontos P-01 (50,2 UNT) e P-09 (38,0 UNT), sugerindo uma interferência da turbidez na cor aparente.

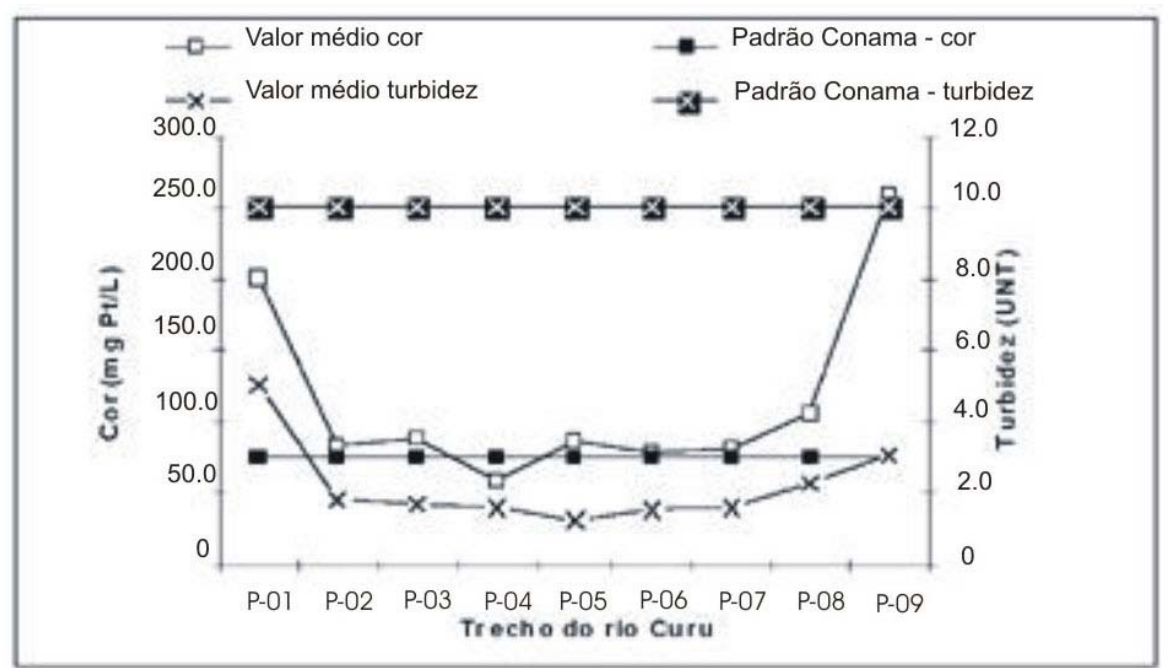

Gráfico 1. Valores médios de cor aparente e turbidez ao longo do rio Curu 
$\mathrm{Na}$ bacia do rio Curu os parâmetros cor e turbidez são influenciados predominantemente por fatores naturais. A área de influência do açude General Sampaio (P-1) caracteriza-se por ser uma depressão envolta por vertentes íngremes e moderadamente desmatadas, o que provoca um constante carreamento de sedimentos, processo intensificado durante a quadra chuvosa $\left(1^{\circ}\right.$ semestre do ano). No perímetro irrigado Curu-Paraipaba (P-09), sabe-se que o principal solo encontrado é o Argissolo Vermelho-Amarelo que possui textura predominantemente argilosa (DEPARTAMENTO NACIONAL DE OBRAS CONTRA AS SECAS, 1993). Levando-se em consideração as condições naturais do solo e as práticas de manejo inadequadas, durante o período chuvoso os processos erosivos são agravados e podem gerar a remoção de maiores quantidades de sedimentos argilosos, alterando a cor e a turbidez dos corpos hídricos presentes.

Em relação ao OD (Oxigênio Dissolvido), o Gráfico 2 mostra que somente o ponto à jusante da sede do município de General Sampaio (P-02) não atendeu ao padrão CONAMA n $357\left(\geq 5 \mathrm{mg} / \mathrm{LO}_{2}\right.$ ) (CONSELHO NACIONAL DE MEIO AMBIENTE, 2005), sendo que o valor encontrado $\left(2,9 \mathrm{mg} / \mathrm{LO}_{2}\right)$ pode ser associado às péssimas condições de infra-estrutura de saneamento básico da sede municipal, onde o rio Curu é o corpo receptor de grande carga orgânica oriunda dos esgotos sanitários e de outras fontes de poluição difusa. Já o ponto localizado na drenagem do perímetro irrigado Curu-Paraipaba (P-09) apresentou um valor médio no limite estabelecido pela legislação $\left(5,1 \mathrm{mg} / \mathrm{LO}_{2}\right)$.

Quanto à $\mathrm{DBO}_{5}$ (Demanda Bioquímica de Oxigênio), todos os pontos de coleta analisados ao longo do rio Curu atenderam ao limite padrão do CONAMA $(\leq 5 \mathrm{mg} / \mathrm{L}$ $\mathrm{O}_{2}$ ), (CONSELHO NACIONAL DE MEIO AMBIENTE, 2005) podendo-se destacar o P-02, no município de General Sampaio, que apresentou o maior valor $(4,6 \mathrm{mg} / \mathrm{L}$ $\mathrm{O}_{2}$ ).

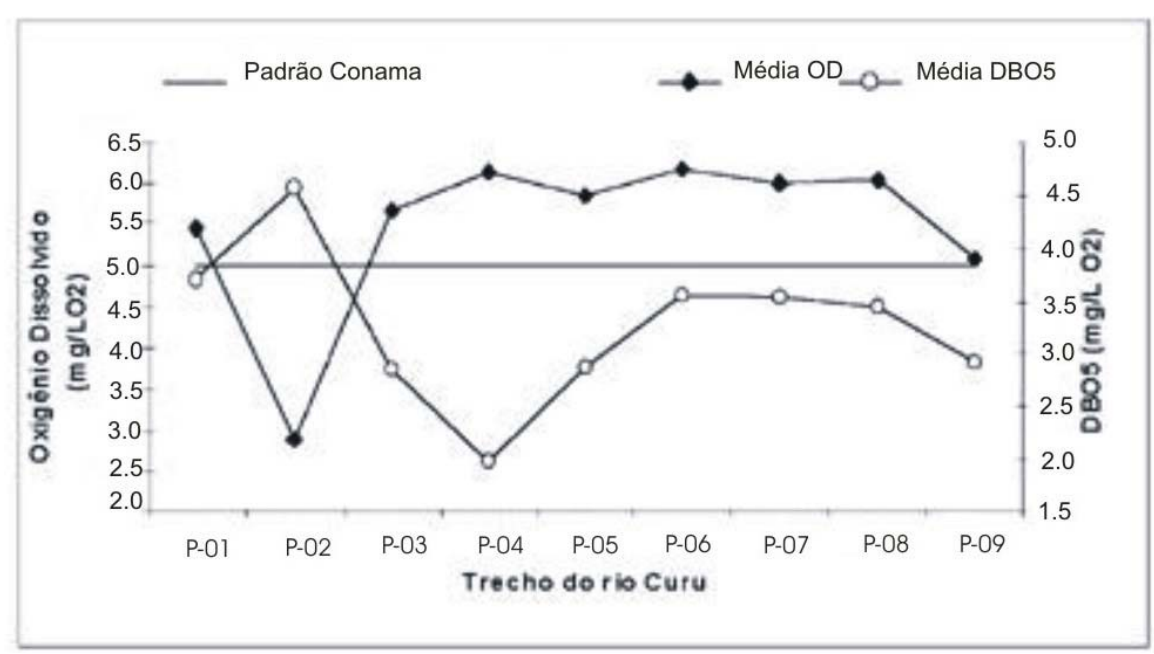

Gráfico 2. Valores médios de $\mathrm{DBO}_{5}$ e $\mathrm{OD}$ ao longo do rio Curu 
Em relação aos valores médios de coliformes termotolerantes analisados nos nove pontos de coleta fluvial, pode-se observar no Gráfico 3 que os índices mais baixos foram encontrados no trecho P-06 (40 NMP/100mL), no município de Paraipaba, área de pouca influência das atividades antrópicas. Os pontos P-03 (2700 $\mathrm{NMP} / 100 \mathrm{~mL})$ e P-04 (1045 NMP/100mL), localizados no município de Apuiarés, apresentaram concentrações médias acima do estabelecido pelo CONAMA (CONSELHO NACIONAL DE MEIO AMBIENTE, 2005) para as águas de Classe 2 $(1000 \mathrm{CT} / 100 \mathrm{~mL})$.

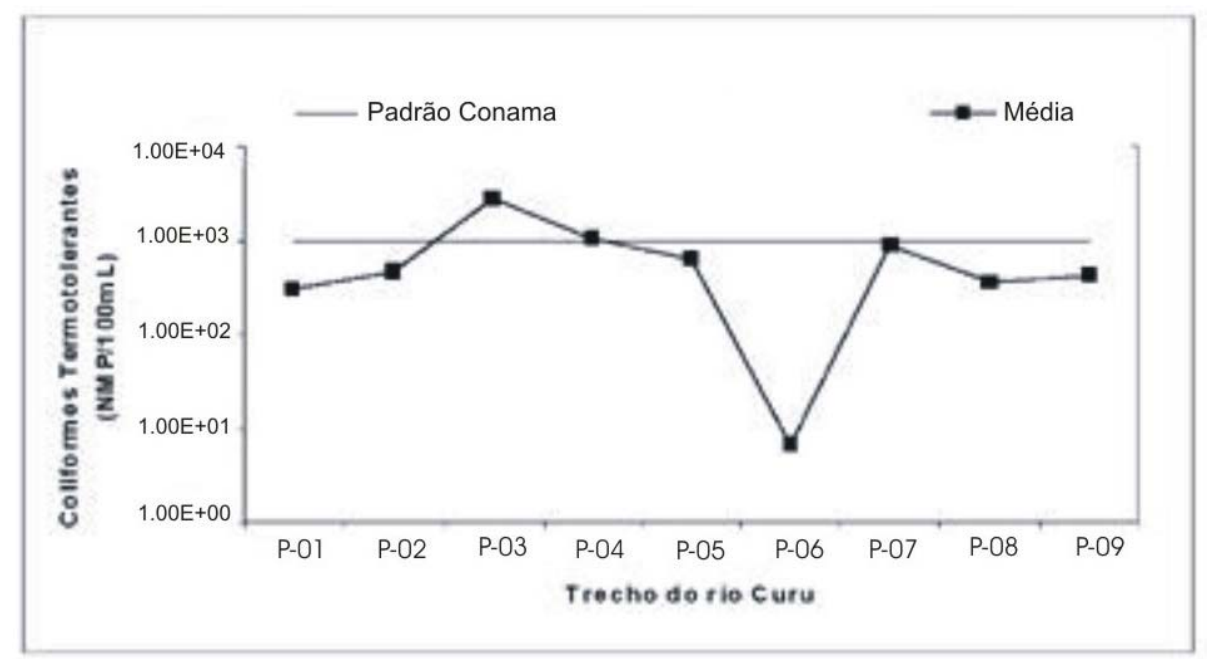

Gráfico 3.Valores médios de coliformes termotolerantes ao longo do rio Curu

O Gráfico 4 demonstra que a concentração média de fósforo total encontrada ao longo do rio Curu apresentou-se fora do padrão estabelecido pelo CONAMA (CONSELHO NACIONAL DE MEIO AMBIENTE, 2005) para ambientes lóticos $(0,1 \mathrm{mg} / \mathrm{LP})$, com exceção do ponto P-02 $(0,09 \mathrm{mg} / \mathrm{LP})$, em General Sampaio, que apresentou valor abaixo e do P-04 que ficou no limite $(0,1 \mathrm{mg} / \mathrm{L} \mathrm{P})$. Os valores mais altos foram encontrados nos pontos das áreas de maior influência das atividades agrícolas, como por exemplo, o ponto P-07 $(0,17 \mathrm{mg} / \mathrm{L} \mathrm{P})$, localizado à jusante dos canaviais das empresas Ypióca e Agrovale, podendo-se associar a este resultado o uso de fertilizantes nas culturas irrigadas, além de outras fontes de poluição difusa.

Todas as estações ao longo do rio Curu atenderam ao padrão estabelecido pela legislação para o nitrogênio amoniacal, tendo em vista que o percentual de amônia livre $\left(\mathrm{NH}_{3}\right)$, forma tóxica à vida aquática, altera conforme as diferentes faixas de $\mathrm{pH}$. Para a maioria dos pontos de coleta, os valores de $\mathrm{pH}$ encontrados na água do rio apresentaram-se em torno de 8 , sendo observado o valor padrão de nitrogênio amoniacal total 2,0 mg/LN. Para os pontos P-01 $(7,4)$, P-07 $(7,3)$ e P-09 $(7,4)$, que apresentaram $\mathrm{pH}$ mais baixo, o padrão de referência considerado foi o de $3,7 \mathrm{mg} / \mathrm{L}$. O Gráfico 5 ilustra as informações descritas anteriormente. 


\begin{tabular}{|l|r|}
\hline Recebido em: $30 / 06 / 2006$ & HOLOS Environment, v.7 n.2, 2007 - P. 116 \\
\hline Liberado para Publicação em: $10 / 12 / 2007$ & ISSN:1519-8634 (ON-LINE) \\
\hline
\end{tabular}

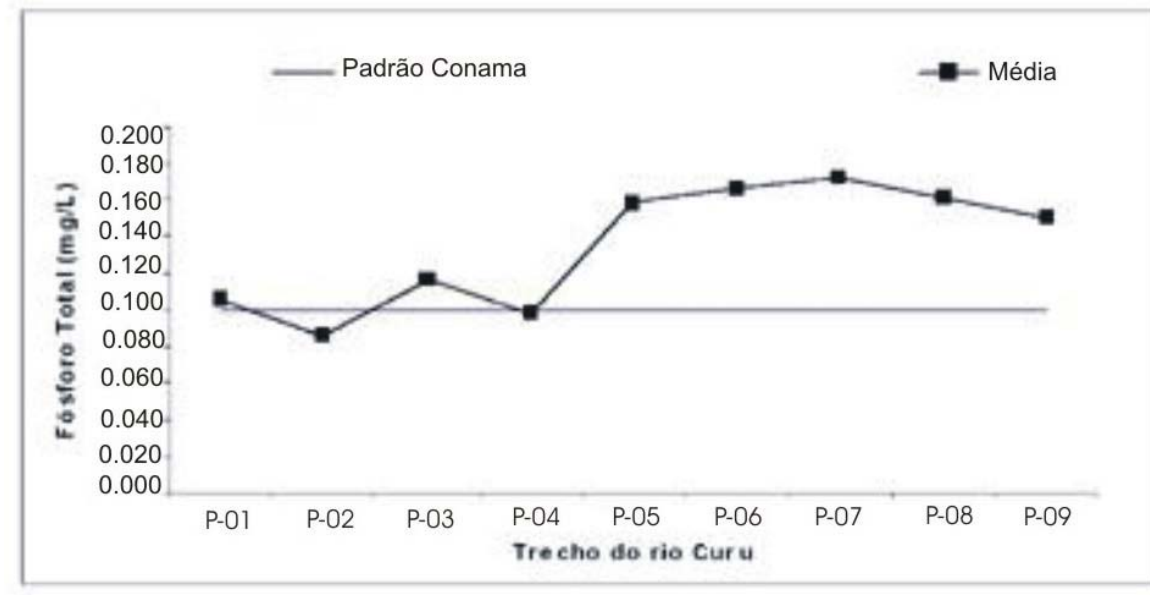

Gráfico 4. Valores médios de fósforo total ao longo do rio Curu

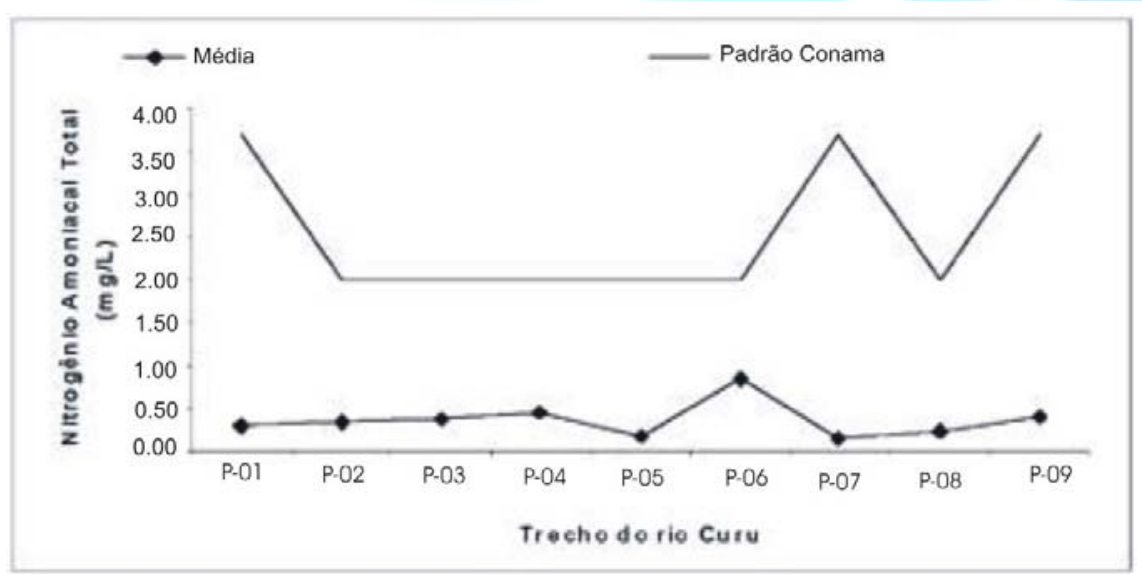

Gráfico 5.Valores médios de nitrogênio amoniacal total ao longo do rio Curu

3.3. Qualidade das Águas Superficiais nos Principais Reservatórios da Bacia do Curu

As análises de água dos principais reservatórios da bacia do Curu revelaram, em relação ao parâmetro cor aparente, resultados semelhantes aos encontrados nas águas ao longo do rio Curu (Gráfico 6). O único reservatório que atendeu ao padrão CONAMA (75 mgPt/L) (CONSELHO NACIONAL DE MEIO AMBIENTE, 2005) foi a Lagoa Cana-Brava (R-07), 36,4 mgPt/L, no município de Paraipaba. Quanto a turbidez, todos os locais de amostragem atenderam aos padrões referentes à Classe 2 (100 UNT), sendo os valores mais altos observados no açude General Sampaio (R02), 50,2 UNT, manancial de abastecimento das cidades de General Sampaio e Paramoti, e no açude Frios (R-06), 58,0 UNT, que compõe o sistema de abastecimento de água dos dois perímetros irrigados (Gráfico 7). 


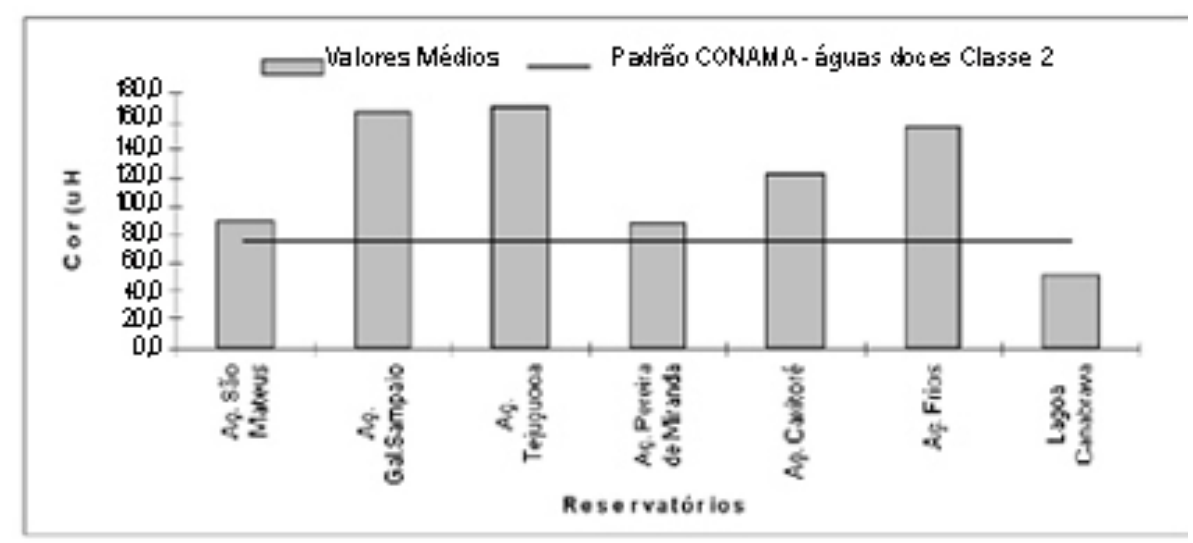

Gráfico 6. Valores médios de cor aparente nos principais reservatórios da Bacia do Curu

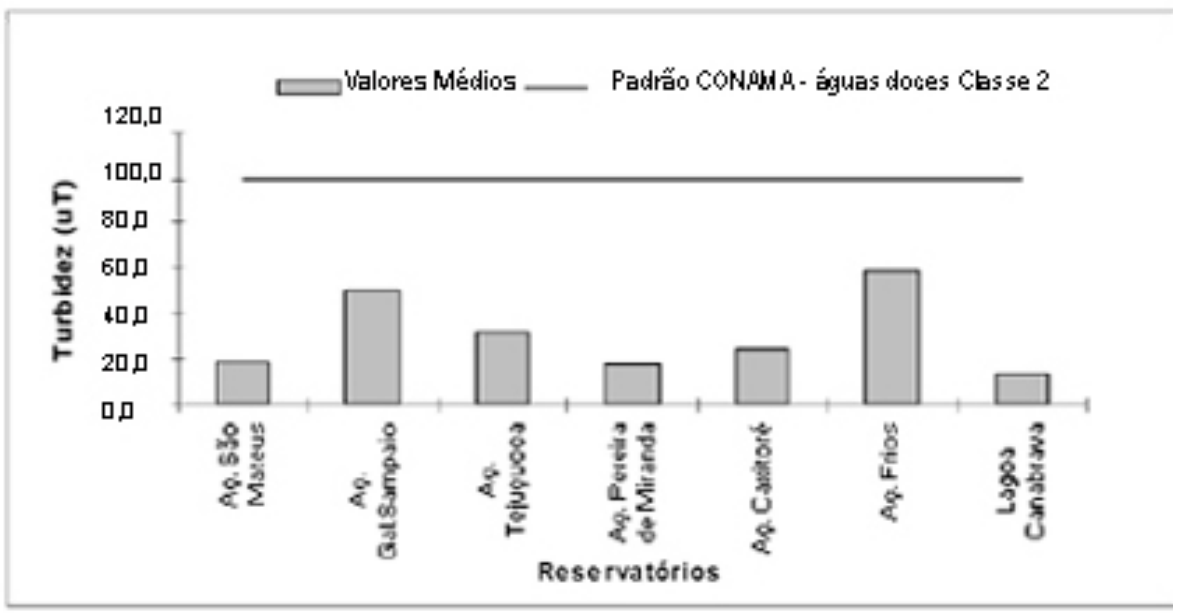

Gráfico 7. Valores médios de turbidez nos principais reservatórios da Bacia do Curu

As variações de $\mathrm{OD}$ e $\mathrm{DBO}_{5}$ são o reflexo do aporte de matéria orgânica no corpo hídrico e estão diretamente relacionados com os processos de fotossíntese, de respiração e/ou de decomposição (ESTEVES, 1988). O valor de OD é indicador de desequilíbrio dos ecossistemas aquáticos e quando atinge valores muito baixos pode acarretar sérios danos à biota, além da água tornar-se imprópria a diversos usos. $\mathrm{O}$ Gráfico 8 mostra que o açude Tejuçuoca (R-03) e a Lagoa Cana-Brava (R-07) encontram-se no limite estabelecido pela legislação $(5 \mathrm{mg} / \mathrm{L})$. Com relação à $\mathrm{DBO}_{5}, \mathrm{o}$ Gráfico 9 demonstra que todos os reservatórios atenderam ao padrão estabelecido, sendo que o açude São Mateus (R-01) e o açude Tejuçuoca (R-03), no local de captação de água da cidade, apresentaram valores entre 4 e $5 \mathrm{mg} / \mathrm{L} \mathrm{O}_{2}$. 


\begin{tabular}{|l|r|}
\hline Recebido em: $30 / 06 / 2006$ & HOLOS Environment, v.7 n.2, 2007 - P. 118 \\
\hline Liberado para Publicação em: $10 / 12 / 2007$ & ISSN:1519-8634 (ON-LINE) \\
\hline
\end{tabular}

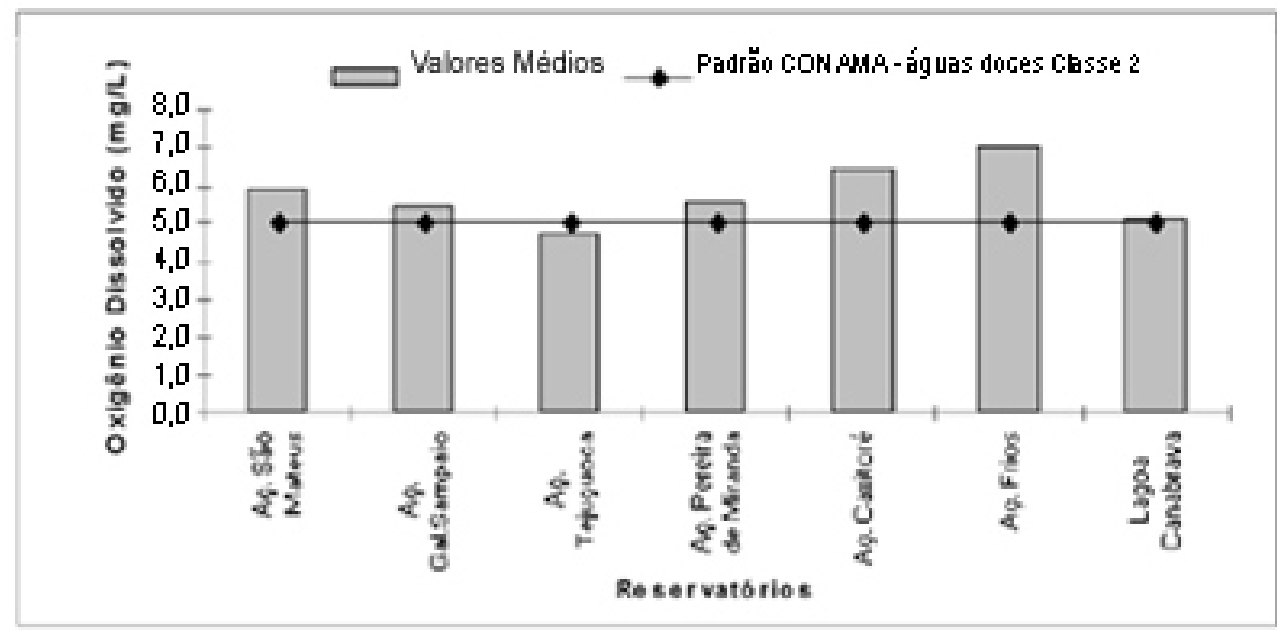

Gráfico 8. Valores médios de OD nos principais reservatórios da Bacia do Curu

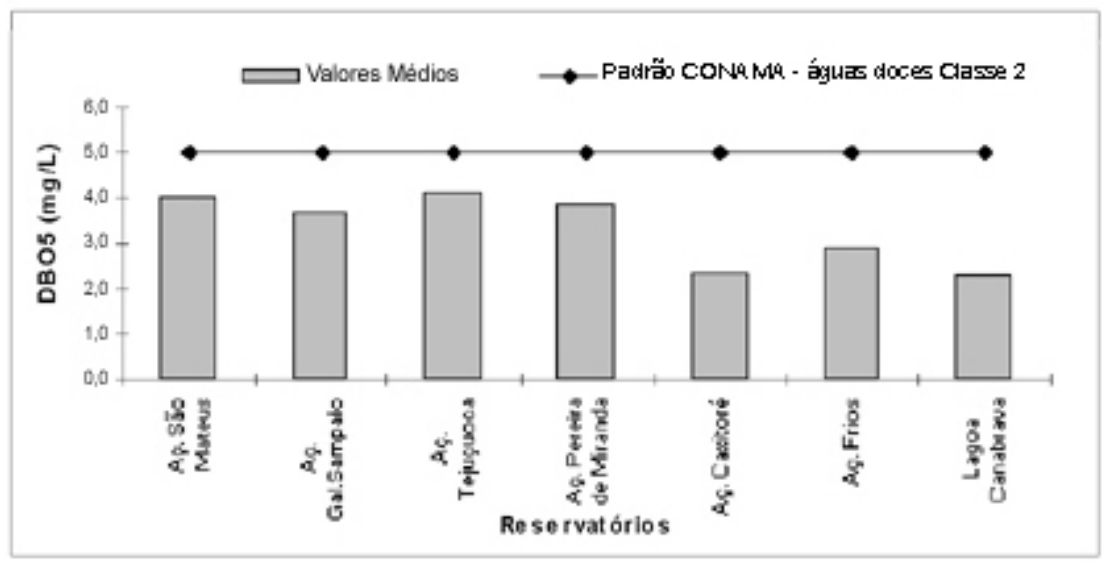

Gráfico 9.Valores médios de $\mathrm{DBO}_{5}$ nos principais reservatórios da Bacia do Curu

Os coliformes termotolerantes são indicadores de contaminação fecal e as águas que possuem níveis elevados dessas bactérias representam risco à saúde humana e ao meio aquático, pois sugerem a presença de patógenos (COMPANHIA DE TECNOLOGIA DE SANEAMENTO AMBIENTAL, 2004b). Dos sete reservatórios analisados, apenas os açudes Pereira de Miranda - R-04 (60 $\mathrm{NMP} / 100 \mathrm{~mL})$ e Caxitoré - R-05 (82 NMP/100mL) apresentaram concentração média de coliformes termotolerantes abaixo do padrão CONAMA n ${ }^{\circ} 357(1000 \mathrm{CT} / 100 \mathrm{~mL})$ (CONSELHO NACIONAL DE MEIO AMBIENTE, 2005). Deve-se considerar que os reservatórios da bacia do rio Curu recebem a poluição gerada nas cidades e a poluição difusa da zona rural. Observa-se também a ocupação indevida de suas margens por bares e restaurantes com infra-estrutura sanitária precária, bem como a existência de criatórios de animais que contribuem para os índices elevados de coliformes. No aspecto de saúde pública, a deterioração da qualidade hídrica na bacia do Curu é agravada pela não utilização do tratamento convencional da água (Classe 2), recomendado para o consumo humano. O levantamento de campo, realizado durante a pesquisa, constatou que o único município que realiza o tratamento 
completo (floculação, decantação, filtração e desinfecção) é Canindé. O restante dos municípios adota apenas o tratamento simplificado (filtração e desinfecção), sendo que em Paracuru, Itatira e Paramoti é adicionado sulfato de alumínio. O Gráfico 10 ilustra as informações expostas anteriormente.

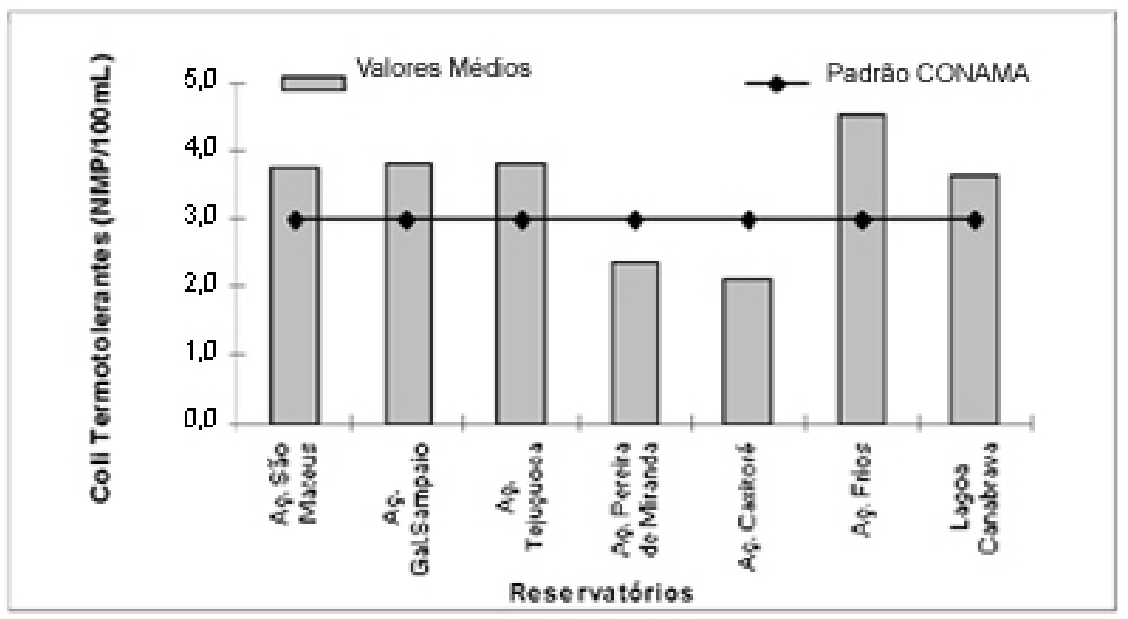

Gráfico 10. Valores médios de coliformes termotolerantes nos principais reservatórios da Bacia do Curu

A quantidade de fósforo total na água está associada diretamente ao processo de eutrofização dos corpos hídricos, que gera o desenvolvimento desordenado de espécies de fitoplâncton com floração de algas tóxicas. O Gráfico 11 demonstra que nenhum ponto de coleta atendeu ao padrão de fósforo total, mas alguns pontos apresentaram-se mais críticos, como o açude Tejuçuoca (R-03), 0,16 mg/L, que abastece a cidade de mesmo nome e o açude Caxitoré (R-05), 0,18 mg/L, manancial de abastecimento público da cidade de Umirim. O Caxitoré encontra-se em processo de eutrofização acelerada, constatado pela presença de grande quantidade de macrófitas cobrindo o espelho d'água. O cenário apresentado pelo reservatório tem como fatores agravantes: i) a contribuição dos riachos São Francisco e São Miguel que atravessam a cidade de Itapajé (à montante do açude) e servem de corpo receptor para os efluentes gerados; ii) a criação de Tilápia do Nilo (Oreochromis niloticus) em tanques-rede dentro do açude e iii) o grande número de comunidades ribeirinhas sem infra-estrutura de saneamento básico. 


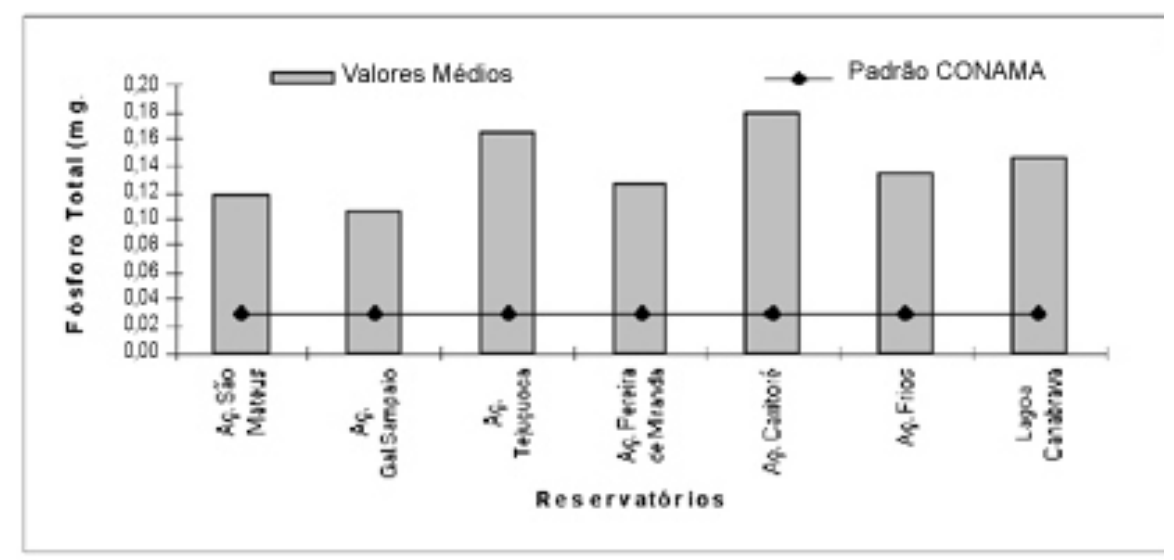

Gráfico 11.Valores médios de fósforo total nos principais reservatórios da Bacia do Curu

Por outro lado, analisando o Gráfico 12 pode-se observar que, ao contrário do que acontece com o fósforo total, os valores de nitrogênio amoniacal em todos os reservatórios atenderam ao padrão estabelecido pela legislação.

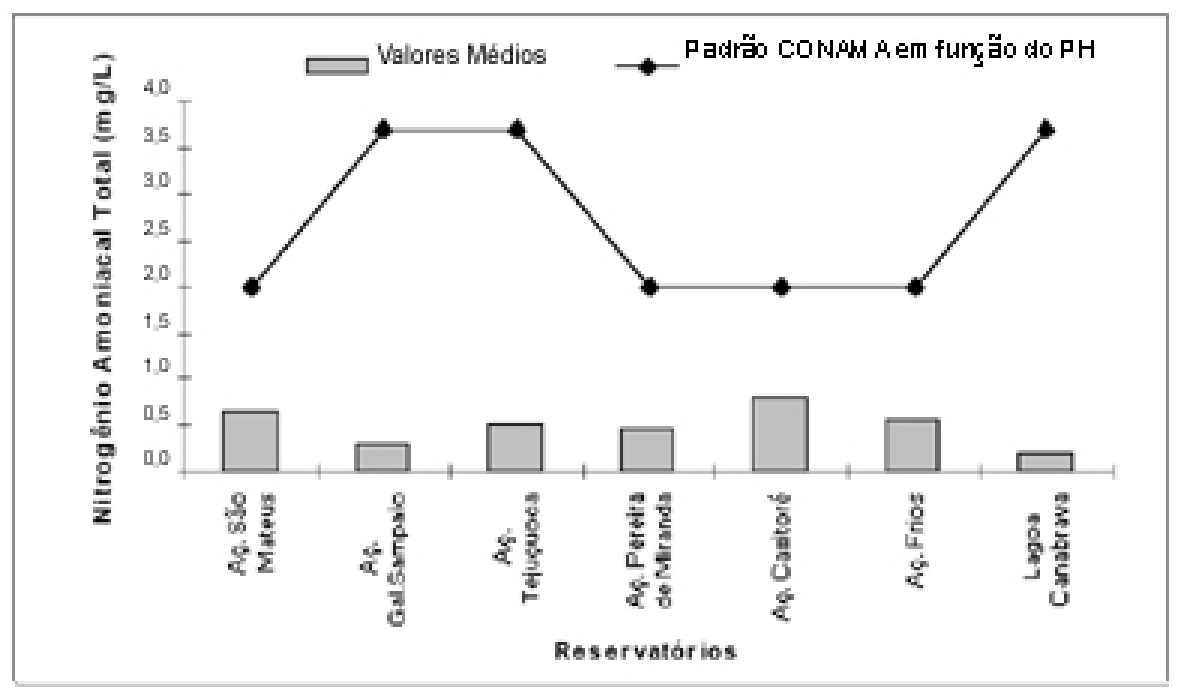

Gráfico 12. Valores médios de nitrogênio amoniacal total nos principais reservatórios da Bacia do Curu

\section{CONCLUSÃO}

Com base nos resultados obtidos conclui-se que os principais fatores que delineiam o cenário encontrado dos recursos hídricos superficiais da bacia hidrográfica do Curu são: o desmatamento, a não observância das legislações que ordenam as APP's (Áreas de Proteção Permanente), a disposição inadequada dos resíduos sólidos, o lançamento de efluentes de ETA's e ETE's, o lançamento de 
esgotos brutos de origem doméstica e hospitalar em corpos hídricos, o lançamento de efluentes de matadouros públicos, de viveiros de camarão e de drenagem dos perímetros irrigados.

Portanto, medidas de controle devem ser adotadas visando à preservação dos recursos hídricos e à reversão das pressões ambientais, principalmente nas áreas de influência dos mananciais de abastecimento humano. No entanto, deve-se considerar que qualquer ação conservacionista de caráter corretivo e/ou preventivo deve integrar todas as esferas sociais e articular políticas públicas com as ações do Comitê da Bacia.

$\mathrm{O}$ ato de diagnosticar a qualidade das águas superficiais, apontando suas fontes potenciais e reais de degradação dos recursos hídricos, apresenta-se aqui como uma ferramenta para a viabilização do desenvolvimento econômico e social da bacia hidrográfica do rio Curu. Assim, este estudo pretendeu contribuir para o planejamento regional da bacia, entendendo que a sociedade é parte integrante do meio em que vive.

\section{AGRADECIMENTOS}

Os autores agradecem ao Mestrado Acadêmico em Geografia da Universidade Estadual do Ceará (UECE), pelo suporte acadêmico, ao Laboratório Integrado de Águas de Mananciais e Residuárias (LIAMAR) do Centro Federal de Educação Tecnológica do Ceará (CEFET-CE), pelas análises laboratoriais, à Companhia de Gestão dos Recursos Hídricos do Ceará (COMPANHIA DE GESTÃO DOS RECURSOS HÍDRICOS, 1996) e aos integrantes do Comitê da Bacia do Curu, pela colaboração dada durante os trabalhos de campo, e à Fundação Cearense de Apoio ao Desenvolvimento Científico e Tecnológico (FUNCAP), pela concessão da bolsa de pesquisa à primeira autora.

Suporte: Projeto "Gestão Racional de Bacias Hidrográficas na Região de Caatinga de Modo a Manter seu Uso Sustentável na Agricultura Irrigada" (PRODETAB), financiado pelo Banco Mundial.

\section{REFERÊNCIAS}

AMERICAN PUBLIC HEALTH ASSOCIATION; AMERICAN WATER WORKS ASSOCIATION; WATER ENVIRONMENTAL FEDERATION. Standard methods for the examinations of water and wasterwater. Washington, 1998.

BRASIL. Ministério da Saúde. Portaria n. 518, de 25 de março de 2004. Dispõe sobre os procedimentos e responsabilidades relativos ao controle e vigilância da qualidade da água para consumo humano e seu padrão de potabilidade. Disponível 
em: http://www.funasa.gov.br/sitefunasa/legis/pdfs/portarias_m/pm_518_2004.pdf. Acesso em: 10 jun. 2004.

COMPANHIA DE ÁGUA E ESGOTO DO CEARÁ. Contas de abril/2004: ligações reais de água. Paraipaba, abril/2004a.

COMPANHIA DE TECNOLOGIA DE SANEAMENTO AMBIENTAL. Variáveis de qualidade das águas. Disponível em: http://www.cetesb.sp.gov.br/agua/rios/variaveis. Acesso em: 11 out. $2004 b$.

COMPANHIA DE GESTÃo DOS RECURSOS HÍDRICOS. Plano diretor da Bacia do Curu. v. I, tomo I. Fortaleza, 1996.

CONSELHO NACIONAL DE MEIO AMBIENTE. Resolução n. 357, de 17 de março de 2005. Dispõe sobre a classificação dos corpos de água e diretrizes ambientais para o seu enquadramento, bem como estabelece as condições e padrões de lançamento de efluentes, e dá outras providências. Disponível em: http://planeta.terra.com.br/educacao/kenya/legis/resolconama001.htm. Acesso em: 20 mar. 2005.

DEPARTAMENTO NACIONAL DE OBRAS CONTRA AS SECAS. Estudo de operação conjunta de reservatórios da Bacia do Curu. Fortaleza, 1993.

DIETRICH, S.; MASCARENHAS, S.; VALEIRAS, N. O estudo de bacias hidrográficas: uma estratégia para educação ambiental. São Paulo: RIMA, 2004.

ESTEVES, F. A. Fundamentos de limnologia. Rio de Janeiro: Interciência, FINEP, 1988.

GORAYEB, A. Análise geoambiental e dos impactos na bacia hidrográfica do rio Curu, Ceará, Brasil. 2004. 141 f. Dissertação (Mestrado em Geografia) Universidade Estadual do Ceará, Fortaleza, 2004.

INSTITUTO BRASILEIRO DE GEOGRAFIA E ESTATÍSTICA. Cidades @: 2000. Disponível em: http://www.ibge.gov.br/cidadesat/topwindow.htm?0 Acesso em: 15 fev. 2004.

FUNDAÇÃO INSTITUTO DE PLANEJAMENTO DO CEARÁ. Atlas do Ceará. Fortaleza, 1989. Escala 1:1.500.000.

LUCENA, R. P.; ROSA, M. F.; FIGUEIRÊDO, M. C. B. Saneamento e qualidade de vida na bacia hidrográfica do Curu - Ceará. Fortaleza: [S.n.], 2004. 